Article

\title{
Ancient Organic Residues as Cultural and Environmental Proxies: The Value of Legacy Objects
}

\author{
Andrew J. Koh ${ }^{1, * \mathbb{D}}$ and Kathleen J. Birney ${ }^{2}$ \\ 1 Center for Materials Research in Archaeology and Ethnology, Massachusetts Institute of Technology, \\ Cambridge, MA 02139-4307, USA \\ 2 Department of Classical Studies and Archaeology Program, Wesleyan University, Middletown, \\ CT 06459-3207, USA; kbirney@wesleyan.edu \\ * Correspondence: akoh@mit.edu
}

Received: 23 December 2018; Accepted: 24 January 2019; Published: 27 January 2019

\begin{abstract}
Often treated as an accessory science, organic residue analysis (ORA) has the capacity to illuminate otherwise hidden aspects of ancient technology, culture, and economy, and therein can play a central role in archaeological inquiry. Through ORA, both the intact vessel freshly excavated from a tomb and the sherd tucked away in a museum storage closet can offer insights into their contents, their histories, and the cultures that created them-provided the results can be carefully calibrated to account for their treatment during and after excavation. The case study below presents ORA data obtained from a range of artifacts from Late Bronze Age Crete, setting results from freshly-excavated and legacy objects alongside one another. Although legacy objects do tend to yield diminished results from both a quantitative and qualitative perspective, our comparative work has demonstrated both their value and untapped potential when their object biographies are carefully considered. It also sheds light on biomarker degradation processes, which have implications for methodologies of extraction and interpretation of legacy objects. Comparative studies such as these broaden the pool of viable ORA candidates, and therein amplify ORA's ability to reveal patterns of consumption as well as ecological and environmental change. They also highlight the role and value of data-sharing in collaborative environments such as the OpenARCHEM archaeometric database.
\end{abstract}

Keywords: organic residue analysis (ORA); archaeochemistry; phytochemistry; ethnobotany; ethnohistory; paleoenvironment; paleoecology; legacy artifacts; perfumed oils; Minoan Crete; OpenARCHEM

\section{Introduction}

Although often viewed as a scientific "sidecar", organic residue analysis (ORA) is gradually becoming a core component of archaeological research design, as its capacity to illuminate otherwise invisible data becomes increasingly evident. Since 2003, the ARCHEM project has collected and curated thousands of ORA field samples taken from ancient artifacts at sites across the eastern Mediterranean and western Asia, including Greece, Israel, Turkey, and Egypt. These include not only samples extracted in the field from freshly-excavated objects (typically, though not exclusively, ceramic), but also samples taken from "legacy" objects excavated up to a century prior, and stored in varying conditions in museums or excavation storage facilities. Although legacy objects do tend to yield diminished results from both a quantitative and qualitative perspective (as their compounds are subject to greater degradation), our work has demonstrated both their value and untapped potential as proxies for cultural, commercial, or environmental change when object parameters and biographies are carefully considered [1]. This is best illustrated through comparison between ORA results from freshly-excavated and legacy objects, an approach that offers valuable insight into the processes of 
chemical, environmental, and anthropogenically-induced degradation that affect them; it also has significant implications for future methodologies of sample collection and interpretation.

In the comparative case study below, we present, in parallel, ORA results taken from artifacts excavated at Mochlos and Tourloti, both Late Bronze Age (LBA) sites in East Crete (Figure 1). We offer some preliminary comments on their ramifications for the variable expression of compounds, the significance of vessel topography, and the overarching value of legacy data in ORA studies as a whole. This is the second in a series of short studies undertaken with the ARCHEM library of samples integrated into the OpenARCHEM archaeometric database, a new open-access repository, resource, and publication outlet for archaeometric data [2].

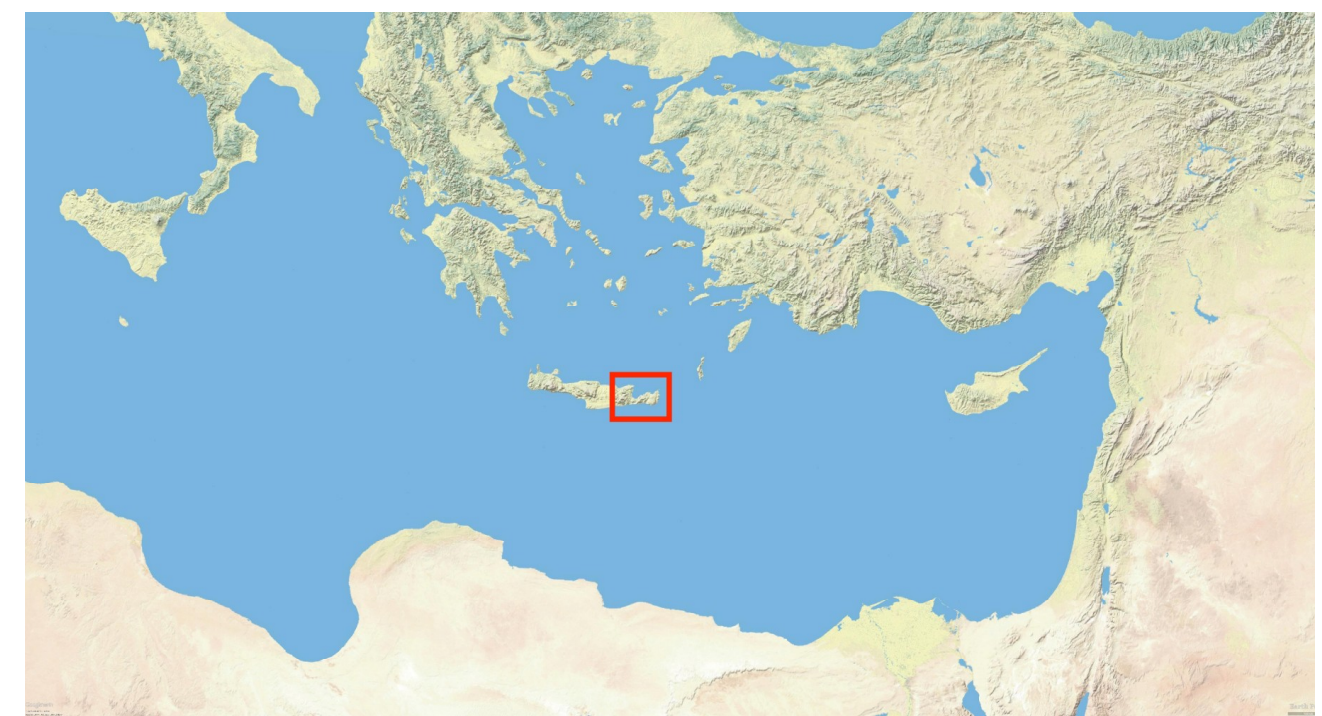

(a)

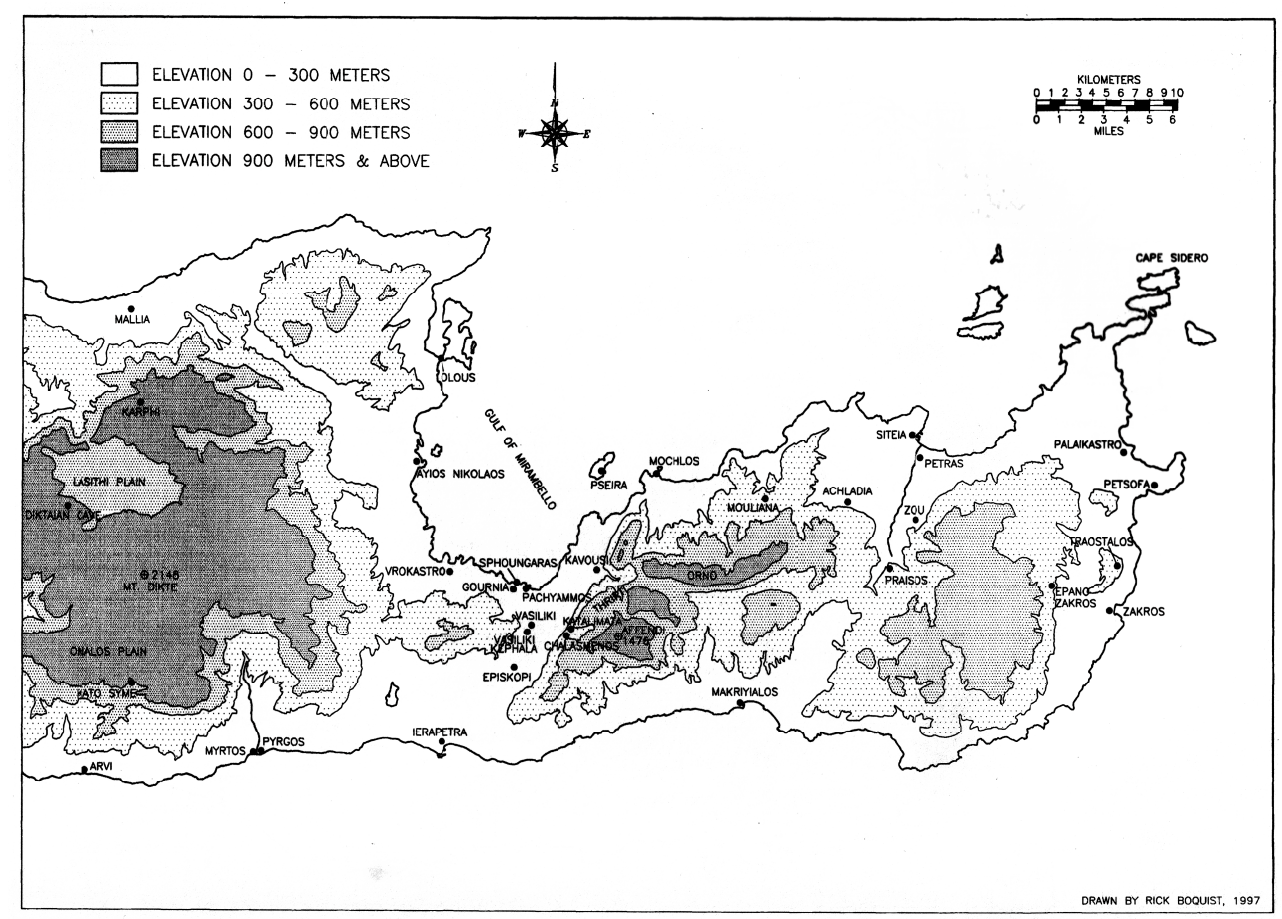

(b)

Figure 1. (a) Map of the eastern Mediterranean. Map data (c) 2019 Google Maps. (b) Map of East Crete. Base map by R. Boquist. Courtesy of J. G. Younger. 


\section{The Tale of Two Perfumes}

In 2004, excavations at the coastal site of Mochlos in East Crete, co-directed by C. Davaras and J. S. Soles, revealed a Late Minoan (LM) IB (ca. 1500 B.C.) perfume workshop, which functioned at the height of the Minoan palaces only to be abandoned after a major LM IB earthquake [3,4]. The perfume manufacturing installation was found largely in situ, and its centerpiece was a complete circular ceramic vat (P6267), ca. $50 \mathrm{~cm}$ in diameter, with a specialized, detachable spout created from a conical vessel ("rhyton"); a fragmentary, undecorated oval-mouthed amphora (P6313A) was found nearby [4]. The amphora was pierced through the bottom in antiquity and may have served as a filter or volumetric standard for bottling the final aromatic product in finer, decorated amphoras. These objects were selected as good candidates for ORA given their likely role in a specialized production process, although its nature was unclear at the time. Once removed from the soil with gloves (typically nitrile) or placed directly into aluminum foil without direct contact, the artifacts were left uncleaned, packaged (some in plastic bags), and transported to the nearby Institute for Aegean Prehistory Study Center in Pacheia Ammos, where organic residues were extracted within two weeks of excavation. The goal was to minimize time between excavation and extraction, and, therefore, to reduce potential for harmful exposure. These precautions, coupled with the careful avoidance of cleaning and conservation prior to sampling, have all been shown to reduce the risk of anthropogenic and environmental contamination, alteration, and degradation while maximizing the potential for significant results [4-6]. Samples were taken according to an early version of the ARCHEM non-destructive extraction protocols described in the methodology section below.

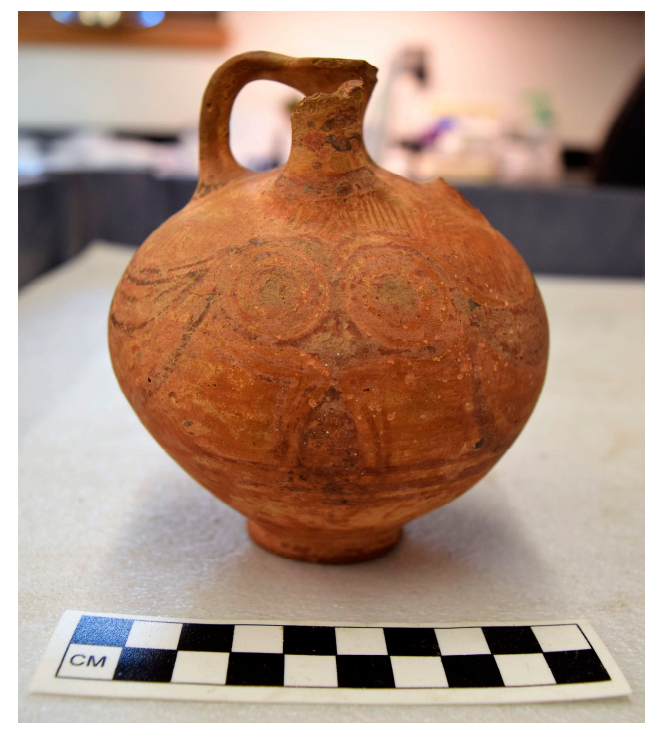

Figure 2. Late Minoan IIIC Early stirrup jar from Tourloti.

In 1905-1906, during excavations of a LM III (ca. 1400-1050 B.C.) cemetery at Tourloti-Plakalona, approximately $4 \mathrm{~km}$ to the southeast of Mochlos, Richard B. Seager [7] uncovered a LM IIIC tomb (ca. 1175 B.C), whose contents included a locally-made stirrup jar (Penn Museum MS4494, Figure 2). This is a small globular, spouted vessel whose twin handles run from its shoulder to attach to a short "false neck" at its top, giving the appearance of stirrups. It is painted in the so-called Close style, and depicts a stylized octopus, an image descended from marine motifs popular in Minoan palatial traditions several centuries prior, but painted in a manner consistent with stylized trends typical for the early 12th century, or LM IIIC Early [1,8]. After excavation, the Tourloti jar was included by Seager in a group of local East Cretan artifacts gifted by the Candia Museum (now the Herakleion Archaeological Museum) to the Free Museum of Science and Art (now the University of Pennsylvania Museum of Archaeology and Anthropology), where it has been in storage since 1906 [9], most recently in modern, enclosed archival cabinets for the past several decades. MS4494 is almost completely intact 
and completely enclosed with only a ca. $5 \mathrm{~mm}$ opening providing access to its interior, and-based on our inspection and according to museum records-has never been displayed, handled excessively, or cleaned aggressively (e.g., scrubbed, acid washed, immersed in water). With a permit from the Penn Museum Scientific Testing Committee, ORA samples were taken from this vessel in 2015, over a century after its original excavation, employing the most recent version of the ARCHEM extraction protocol first applied to the Mochlos objects in 2003 [1,4-6].

\section{Materials and Methods}

OpenARCHEM prioritizes in-field and on-site extractions, for which non-destructive sampling methods are best suited. The value and viability of these approaches have been demonstrated in numerous studies [1,4-6,10-13]. Ancient organic compounds pose a challenge to the archaeological scientist in that, even under ideal conditions, they are prone to volatilization, degradation, and decomposition over time. As such, the diagnostic components of ancient compounds register more weakly than in comparable modern samples. Beyond these naturally occurring processes, archaeological samples are also susceptible to anthropogenic or environmental contamination in their journey from excavation to storage and exhibition, processes that have the potential to further obscure, dilute, or alter chemical signatures. Extraction and instrumentation protocols, if not carefully calibrated, can actually exacerbate these challenges. As such the ARCHEM project has developed and tested methodologies to maximize diagnostic output while minimizing undue risk to the already fragile contents as well as the artifacts themselves.

\subsection{Non-Destructive Extraction Methodologies}

The vessels from both Mochlos and Tourloti were sampled according to ARCHEM extraction protocols [4-6], which were developed utilizing non-destructive precedents $[10,11]$ with field extractions in mind and subsequently refined through years of continuous field-testing [13]. While they share the same fundamental approach, the protocol used for Tourloti [1], being more recent, reflects the latest methodology. This is the product of an additional decade and a half of experimental refinement, which has shown that attention to the preservation, history, and therein potential contamination of an object is essential to the acquisition of qualitatively and quantitatively significant samples. With proper consideration of these features (i.e., a pre-experimental "diagnosis"), sampling strategies can be adapted to improve the collection and contamination and degradation risks likewise factored into interpretive frameworks. Object biography-including excavation conditions in the field - thus was and remains one of the key considerations in our methodology.

The ARCHEM extraction protocols are of two types: "swishing" and "boiling", both of which are non-destructive processes typically utilizing heated absolute, analytical-grade ethanol. Given that some mineral tempers in clay (e.g., calcites) are lipophilic [14], preferentially adsorbing certain fatty organic residues, the introduction of heated solvents induces dissolution of organics from the ceramic matrix. Ethanol is the ideal ORA solvent for field sampling, as it is both the least toxic of all alcohols, mitigating the need for a fume hood, and readily procurable worldwide, even in remote locations. In the early years, ARCHEM employed a two-step extraction process utilizing non-polar and polar solvents in rapid succession (e.g., ethyl acetate and methanol) with the goal of minimizing compounds to separate in each chromatogram $[4,10]$. However, over a decade of research in the field has empirically demonstrated that the downsides of a two-solvent extraction process in the field (e.g., working with highly toxic solvents) typically outweigh any marginal benefits that the more unwieldy solvent systems might provide in certain limited circumstances with ancient organic residues $[5,6]$. Beyond its ready availability and low toxicity, ethanol's solvent properties obviate the need for a two-step extraction process [5], as its hydroxyl group attracts polar and ionic molecules, while its ethyl group attracts non-polar ones. These qualities facilitate the rapid and effective extraction of a broad range of organic residues while leaving the artifact undamaged, making it ideally suited to field extraction. On-site extraction not only allows the ORA specialist to adapt extraction methods 
to the immediate archaeological environment and take regular soil samples as future controls, but also results in a comprehensive library of samples with detailed provenance. This is information that can offer uncommon insight into bigger issues such as the spatial distribution of a particular ancient organic commodity, or help to identify large scale contamination events across a site [13], which are almost always anthropogenically induced.

Boiling extractions are best suited for vessel fragments that have a clear chain of custody. This includes those that have a clean excavation and sampling history (e.g., handled with gloves, isolated in aluminum foil, unwashed) and subsequently have a low probability of contamination on any surface. The isolated fragments are placed in suitably sized Griffin beakers and are immersed in heated ethanol for at least several minutes. The type of pottery fragment makes a difference: For boiling extractions, vessel fragments are optimally chosen from the base, followed by the rim, especially for cookpots [15] or pouring vessels, and then the body, in that order. This is predicated on the assumption that the interiors of bases have the greatest exposure to organics, which pool at the bottom of a vessel or its lowest point at deposition, while certain diagnostic compounds float to the top during its history of use. Care must be taken to ensure that samples extracted from multiple fragments originate from a single object (i.e., that they all join). In cases of uncertainty, or where there are constraints upon resources (time or materials), which necessitate more limited sampling, then a single fragment chosen from the base at a location where it joins the body is usually preferable.

Swishing extractions are better suited for complete and near-complete vessels, or vessel fragments such as large bases, which, given their location on the vessel (as noted above), have typically had more prolonged exposure to organic contents, and therein greater opportunity for extant residues to permeate the matrix of the clay fabric. For the swishing of large vessel fragments, solvents are heated in a beaker as usual (to just below boiling), but they are then poured in small volumes onto the fragment and gently swished and/or stirred for approximately one minute on an interior surface, where the original organic contents would have come into prolonged contact for adsorption. For swishing of largely intact vessels, hot solvent is directly pipetted or poured into vessels, and is immediately swished and/or stirred around the object for up to a minute, and subsequently filtered directly into $20 \mathrm{~mL}$ master scintillation vials. Multiple swish extractions are typically executed.

Here again, object biography makes a difference. For objects with a clear chain of custody, and for which there are no indications of contaminants, all swished extractions can be collected into a single master sample prior to instrumentation. However, as our earlier work has indicated, the longer an object has been unearthed, the more likely the first extraction-those taken from the exposed surface-will include organics suffering from some level of contamination and degradation. Therefore, for those objects whose condition, or biography, is less certain, the swishing process is repeated and each resulting solution sample isolated, in order to moderate the removal of potential contaminants in early stages and facilitate compound separation and identification in multiple chromatograms. This can be a successful method to filter out plasticizers such as phthalates, which tend to appear in the first extraction and diminish or disappear in subsequent ones, as the results from plastic-packaged vessels from other areas of Mochlos and other sites have shown [4].

As freshly excavated artifacts, the Mochlos vessels-which included both complete and fragmentary vessels-were considered at lower risk for environmental degradation and anthropogenic contamination. Four samples were taken from the Mochlos vat and two from the nearby undecorated amphora, for a total of six samples from Mochlos and three from Tourloti (Table 1). Being smaller and more fragmentary, sherds from the vat's rhyton-spout were boiled using the two extraction solvents in sequence, ethyl acetate first followed by ethanol, which produced two samples (Figure 3). The large pieces of the main body of the vat, being too large for beakers, were swished using the two extraction solvents in sequence, which produced two more samples (Figure 4). The undecorated amphora (P6313A) was fragmented, but as the full profile was preserved and the sherds from the base, body, and rim were clearly from the same vessel, these sherds were boiled together first in ethyl acetate followed by ethanol to produce two samples (Figure 5). 
Table 1. Gas Chromatography-Mass Spectrometry data from Tourloti and Mochlos vessels.

\begin{tabular}{|c|c|c|c|c|c|c|c|c|c|c|c|c|c|c|c|}
\hline Vessel & Figure & $\begin{array}{c}\text { Sample ID } \\
\S\end{array}$ & Solvent & $\begin{array}{c}\text { Maximum } \\
\text { Peak } \\
\text { Height }\end{array}$ & $\begin{array}{l}\text { Maximum } \\
\text { Peak AA * }\end{array}$ & $\begin{array}{c}\text { Maximum } \\
\text { Peak } \\
\text { Concentration } \\
(\%) \dagger \\
\end{array}$ & $\begin{array}{l}\text { Cholesterol } \\
\text { RA }(\%) \ddagger\end{array}$ & $\begin{array}{c}\text { Oleic } \\
\text { Acid } \\
\text { RA (\%) } \\
\ddagger \\
\end{array}$ & $\begin{array}{c}\text { Linoleic } \\
\text { Acid } \\
\text { RA (\%) } \\
\ddagger \\
\end{array}$ & $\begin{array}{c}\text { Azelaic } \\
\text { Acid } \\
\text { RA (\%) } \\
\ddagger \\
\end{array}$ & $\begin{array}{c}\text { Cinnamic } \\
\text { Acid RA } \\
(\%) \ddagger\end{array}$ & $\begin{array}{l}\text { Linalool } \\
\text { RA (\%) } \\
\quad \neq\end{array}$ & $\begin{array}{c}\text { Manoyl } \\
\text { Oxide RA } \\
\text { (\%) } \ddagger\end{array}$ & $\begin{array}{l}\text { Docosane } \\
\text { RA }(\%) \ddagger\end{array}$ & $\begin{array}{l}\text { Camphor } \\
\text { RA (\%) }\end{array}$ \\
\hline Mochlos Vat spout (P6267) & $3 a$ & Run 9.06 & ethyl acetate & 12224 & 25516 & 37.49 & trace & trace & 7.12 & 0 & 6.50 & trace & 44.30 & 0 & 7.62 \\
\hline Mochlos Vat spout (P6267) & $3 b$ & Run 2.17 & ethanol/methanol & 20793 & 41916 & 21.06 & 7.40 & 25.20 & 18.10 & 0 & 3.13 & trace & trace & 0 & 20.52 \\
\hline Mochlos Vat Base (P6267) & $4 \mathrm{a}$ & Run 9.05 & ethyl acetate & 9353 & 20609 & 32.08 & 0 & 24.30 & trace & 0 & 15.03 & trace & 49.70 & 8.64 & trace \\
\hline Mochlos Vat Base (P6267) & $4 \mathrm{~b}$ & Run 3.10 & ethanol/methanol & 11574 & 23998 & 47.95 & 0 & 62.50 & 18.00 & 0 & 12.20 & trace & trace & trace & 8.96 \\
\hline $\begin{array}{l}\text { Mochlos amphora } \\
\text { (P6313A) }\end{array}$ & $5 a$ & Run 9.16 & ethyl acetate & 7989 & 14218 & 10.70 & 0 & 20.90 & 22.80 & 0 & 22.10 & 16.60 & trace & 4.66 & 42.40 \\
\hline $\begin{array}{l}\text { Mochlos amphora } \\
\quad(\text { P6313A) }\end{array}$ & $5 b$ & Run 6.14 & ethanol/methanol & 19014 & 39287 & 33.73 & 0 & \#\#\#\# & 53.10 & 0 & 45.80 & 0 & trace & trace & 52.00 \\
\hline Tourloti Jar (MS4944) 1 & $6 \mathrm{a}$ & $\begin{array}{l}\text { ARCHEM } \\
4426\end{array}$ & ethanol & 7586 & 11674 & 41.02 & 0 & 18.70 & $\mathrm{n} / \mathrm{a}$ & 100 & 0 & 14.90 & 19.46 & 0 & 0 \\
\hline Tourloti Jar (MS4944) 2 & $6 \mathrm{~b}$ & $\begin{array}{c}\text { ARCHEM } \\
4427\end{array}$ & ethanol & 6673 & 10907 & 56.60 & 0 & 0 & $\mathrm{n} / \mathrm{a}$ & 100 & 43.54 & 3.28 & 0 & 0 & 4.78 \\
\hline Tourloti Jar (MS4944) 3 & $6 c$ & $\begin{array}{c}\text { ARCHEM } \\
4428\end{array}$ & ethanol & 10231 & 16473 & 37.22 & 0 & 0 & $\mathrm{n} / \mathrm{a}$ & 100 & 0 & 2.64 & 3.34 & 0 & 0 \\
\hline
\end{tabular}

trace $=1-3 \%$, §Run \# (as assigned by Koh 2008) or standard ARCHEM \#, * Absolute Abundance, or peak area determined by integration in chromatograms, + Percentage of the sum of all peaks in a chromatogram, $\ddagger$ Relative Abundance, or peak area as a percentage relative to the maximum peak.

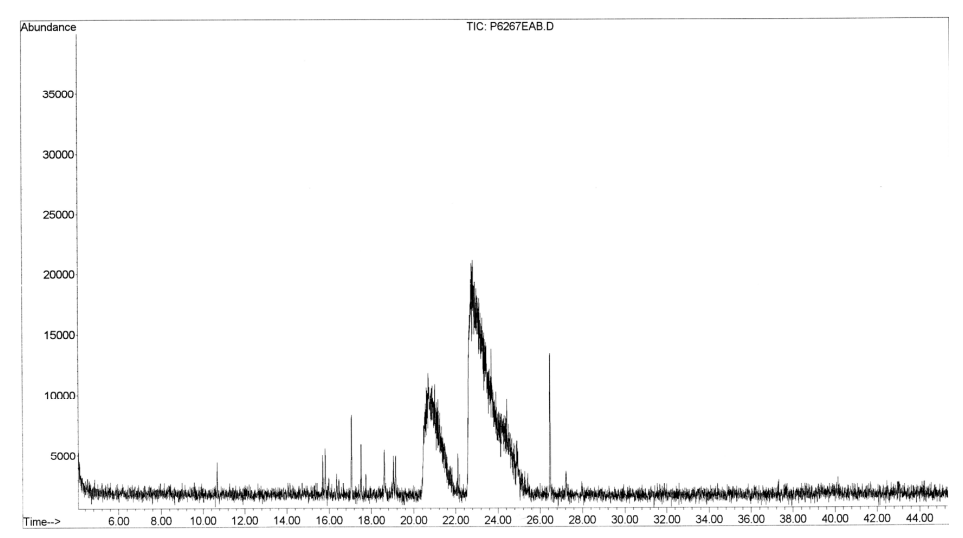

(a)

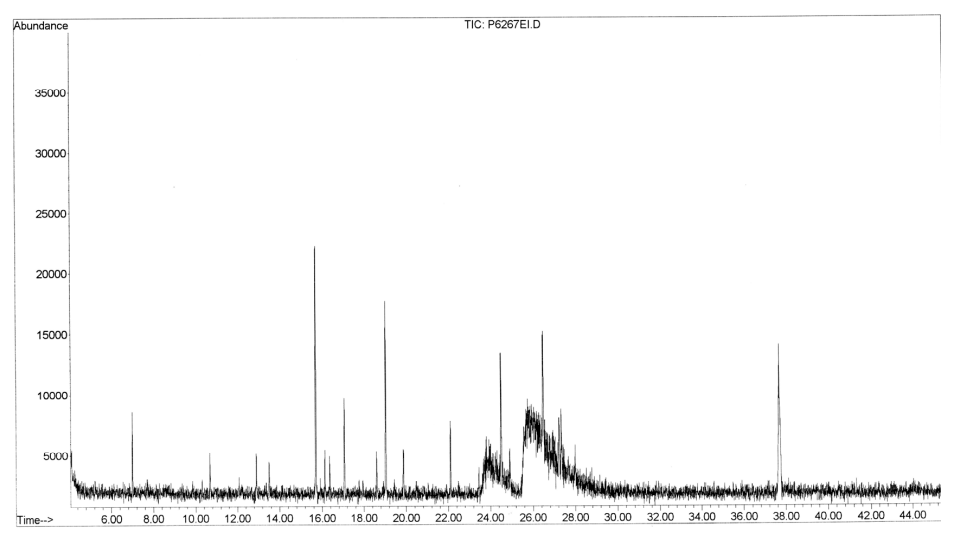

(b)

Figure 3. Total Ion Chromatogram from: (a) ethyl acetate extraction of Mochlos vat spout; (b) ethanol extraction of Mochlos vat spout. 


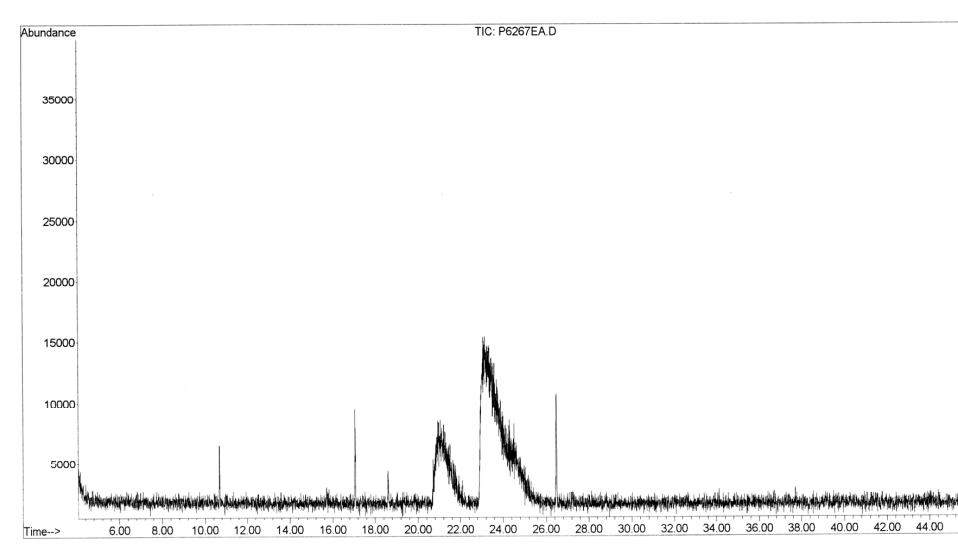

(a)

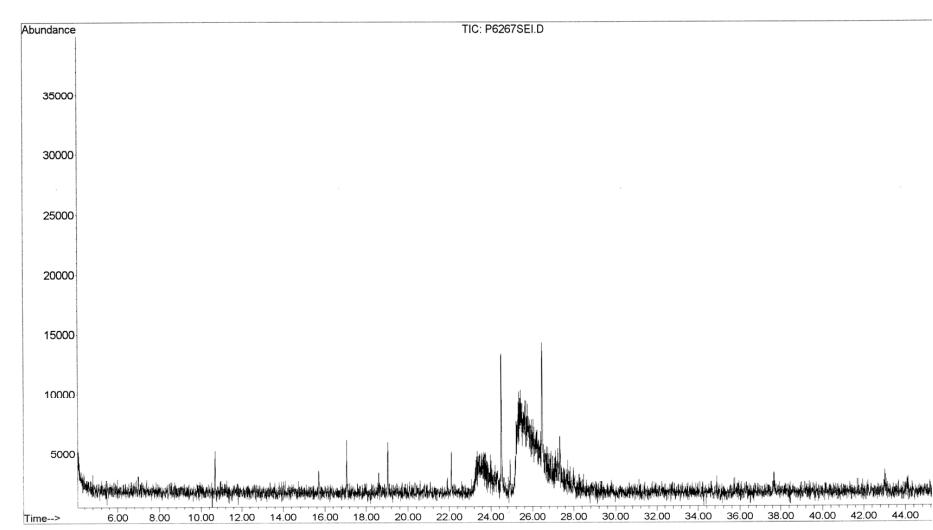

(b)

Figure 4. TIC from: (a) ethyl acetate extraction of Mochlos vat body; (b) ethanol extraction of Mochlos vat body.

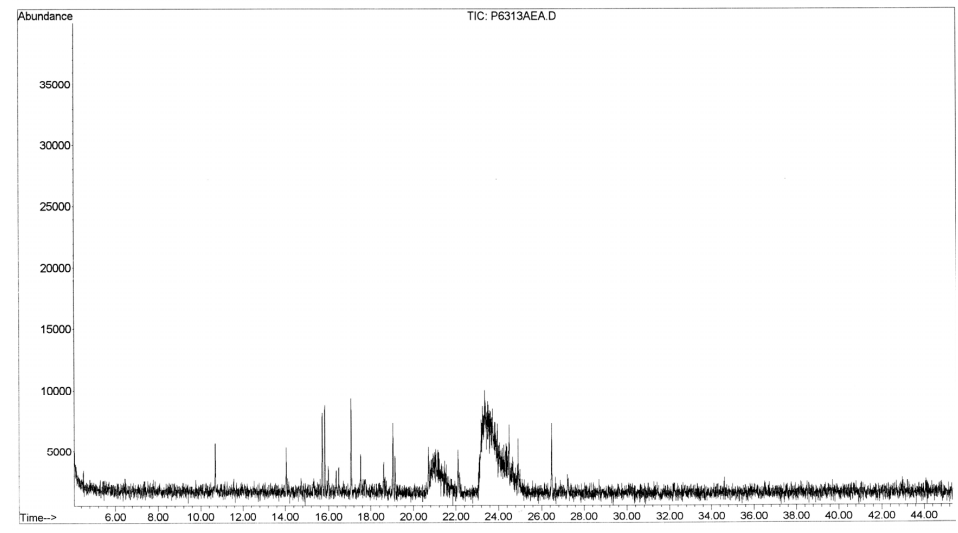

(a)

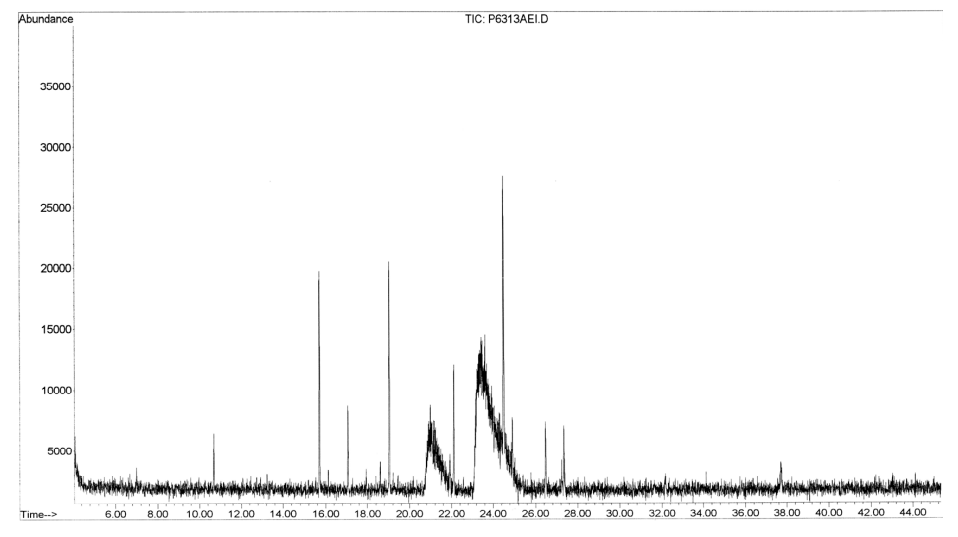

(b)

Figure 5. TIC from: (a) ethyl acetate extraction of Mochlos amphora; (b) ethanol extraction of Mochlos amphora. 


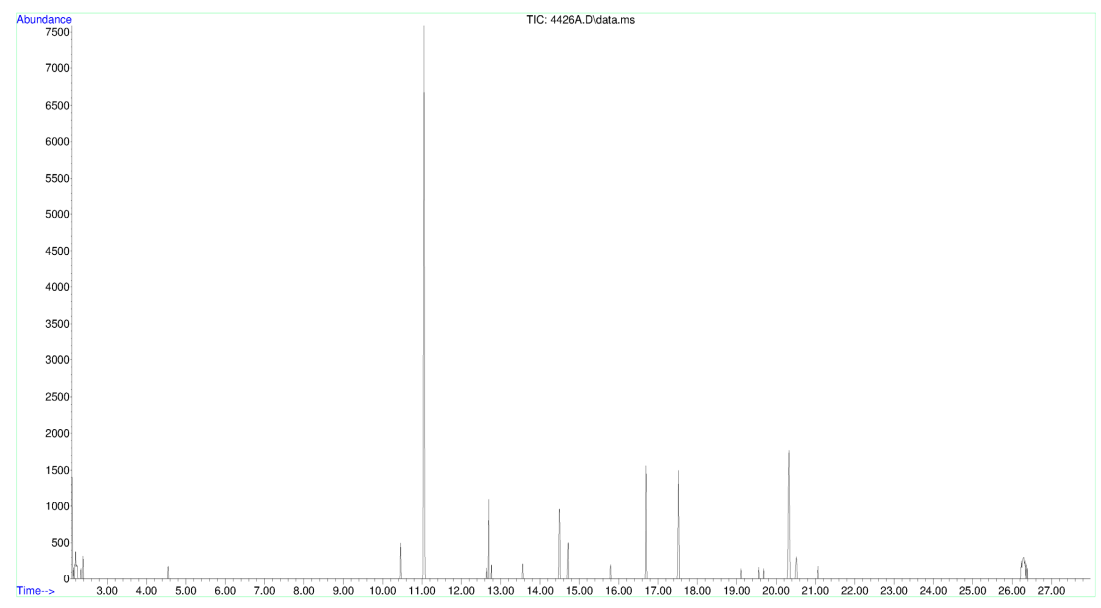

(a)

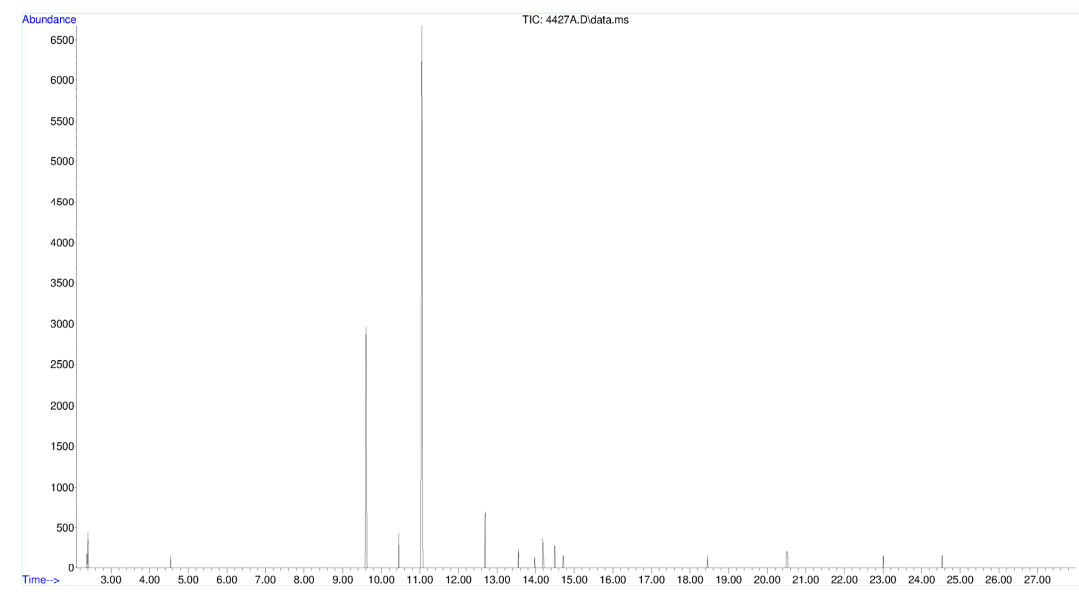

(b)

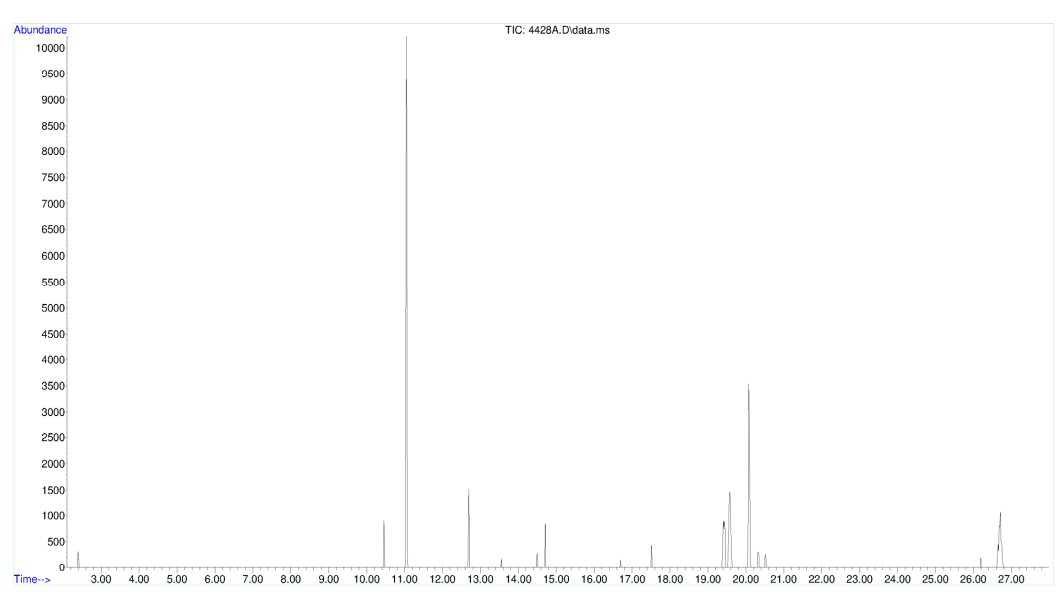

(c)

Figure 6. TIC from: (a) first extraction of MS4494; (b) second extraction of MS4494; (c) third extraction of MS4494. 
The Tourloti jar, by contrast, was sampled over a century after its excavation. The top-flight archaeological museum in which it currently resides now boasts climate-controlled storage; however, the jar certainly experienced more environmentally variable conditions prior to our sampling. Although neither the museum records nor visual inspection showed any signs of cleaning or conservation, it was unclear whether any viable compounds could be extracted from a jar so long exposed after excavation. As an experimental precaution, additional measures were employed to account for the potential buildup of dust or other contaminants on the interior of the vessel, and to maximize the likelihood that residues trapped within the fabric could be chemically extracted: Three separate hot solvent washes (i.e., swishes) were performed in rapid succession despite using the same solvent (i.e., ethanol), resulting in three separate filtered solution samples (Figure 6).

\subsection{Instrumentation Methodology}

The low concentrations of organic compounds preserved in ancient samples demand analytical instruments of high sensitivity, which allow researchers to separate and characterize organic compounds, both qualitatively and quantitatively. Instruments of choice have been chromatographic, especially liquid (LC-MS) or gas chromatography (GC-MS) coupled with mass spectrometry [16-18], with the protocols for each refined for the best expression of fragile and low concentration compounds.

The extracted Mochlos ORA samples, evaporated to dryness, were held in climate-controlled storage until export permissions from the Hellenic Ministry of Culture were granted, after which they were sent at first opportunity to the University of Pennsylvania Department of Chemistry in spring of 2005 [4]. Once safely in Philadelphia, preparations were made to inject the samples into the department's most advanced GC-MS housed in its Mass Spectrometry Facility. These preparations were made at the Roy and Diana Vagelos Laboratories at the invitation of G. Palladino, executive director, and G. A. Molander, the Hirschmann-Makineni Professor of Chemistry. The Mochlos ORA samples were processed and reintroduced into solution using ethyl acetate. Before injection into the Mass Spec Facility GC-MS, general conditions were determined using a HP 5890A Gas Chromatograph interfaced with a HP 3395 Integrator, housed in the Vagelos research laboratories of the Molander Group. This protocol was then further optimized in collaboration with the Molander Group over the course of several weeks using the actual GC-MS at the Mass Spec Facility, an Agilent Technologies 6890N Network 6C System used in series with an Agilent Technologies 5973N Network Mass Selective. Samples were automatically injected with an Agilent Technologies 7683 Series Injector with $10 \mu \mathrm{L}$ syringe, which allowed automated overnight runs and the possibility to analyze hundreds of samples in a compressed time frame. Before the injection of each $2 \mu \mathrm{L}$ sample, the computer automatically cleaned the syringe with $10 \mu \mathrm{L}$ of methylene chloride twice and also primed it twice with the ORA sample pre-injection. Post-injection, the syringe was cleaned four times using $10 \mu \mathrm{L}$ of methylene chloride. The GC-MS had a capillary column $(30.0 \mathrm{~m} \times 250 \mathrm{~mm} \times 0.15 \mathrm{~mm})$ set to constant flow mode and front inlet. The carrier gas flow (helium) was set to $0.5 \mathrm{~mL} / \mathrm{min}$ with an average velocity of $41 \mathrm{~cm} / \mathrm{s}$. The EPC Split-Splitless Inlet was ultimately set to splitless as experimentation demonstrated that the small quantities of ancient compounds present in the circumstances at hand were better expressed in such fashion. The GC oven temperature had a set point of $110^{\circ} \mathrm{C}$ held for two minutes, and increased by $6{ }^{\circ} \mathrm{C} /$ minute until it hit $250{ }^{\circ} \mathrm{C}$, and then held for $20 \mathrm{~min}$, with a total run time of $45.33 \mathrm{~min}$. Solvent blanks were utilized before and after the set to verify that no contaminants existed from previous runs or that components were lost in the column.

The Mass Spec Facility GC-MS was interfaced with a HP Vectra VL420 DT computer (P4 2.20 GHz, $256 \mathrm{mb}$ RAM) running Microsoft Windows 2000 Professional SP 2 (5.00.2195) and Agilent Technologies MSD Enhanced Chemstation (G1701DA version D.00.00.38). The compounds were initially identified using the National Institute of Standards and Technology Mass Spectral Database (NIST 02) with its Mass Spectral Search Program (1.7a) before being manually checked for final peak assignation. In order to help ensure the survival of the molecular ions in sample sizes that were anticipated to be relatively minute, the mass spectrometer was eventually set up for "soft" chemical ionization (CI), instead of 
the harsher electron ionization (EI) more prevalent in labs. This approach made it more laborious to interpret mass spectra since most reference spectra and the computer library searches are EI-based, but the results proved this approach worthwhile in the context of ancient organic residue analysis.

The Tourloti ORA solution samples were transported back to the Brandeis University Department of Chemistry immediately after extraction in August 2015 and processed for instrumentation the following day [1]. The samples were concentrated to solid by rotary evaporator and then redissolved in uninhibited tetrahydrofuran (THF) to produce $\sim 300 \mu \mathrm{L}$ GC-MS analytes, which supplied $4 \mu \mathrm{L}$ for auto injection into an Agilent 7890A GC with a HP-5MS column and a 5975C VL MSD Triple Axis Detector. Before the injection of each sample, the computer automatically cleaned the syringe with $10 \mu \mathrm{L}$ of THF twice, and also primed it twice with the ORA sample pre-injection. Post-injection, the syringe was cleaned two times using $10 \mu \mathrm{L}$ of THF. The pulsed split injector and interface were both set to $250^{\circ} \mathrm{C}$. The initial oven temperature was set to $100{ }^{\circ} \mathrm{C}$ and held for two minutes before reaching $250{ }^{\circ} \mathrm{C}$ at a rate of $10^{\circ} \mathrm{C} /$ minute, at which time it was held for an additional $11 \mathrm{~min}$, giving the total program time of $28 \mathrm{~min} / \mathrm{sample}$. As at Penn Chemistry, solvent blanks were utilized before and after the set to verify that no contaminants existed from previous runs or that components were lost in the column. Within the first sample (ARCHEM 4426), any anticipated dust and dirt were removed by hot filtration during the extraction process. The compounds were initially identified using the NIST Mass Spectral Database (NIST 11) with its Mass Spectral Search Program (2.0 g) before being manually checked for final peak assignation.

\section{Results}

Table 1 presents the comparative results and quantities of the diagnostic compounds recovered from each extraction of the Mochlos and Tourloti vessels. Note that palmitic and stearic acid, although usually represented in all samples, have been omitted from the list of compounds, as they are so ubiquitous in organic samples as to be non-diagnostic. In the Mochlos samples, oleic acid, cinnamic acid, linalool, manoyl oxide, docosane, and camphor were identified after initial peak assignation using the NIST Mass Spectral Database, NIST 02 (Figures 3-5). Each of these compounds can be connected to a high degree of certainty with known botanical sources local to Crete and the eastern Mediterranean. In the Tourloti jar, azelaic acid, oleic acid, linalool, and manoyl oxide were tentatively identified in the first extraction (ARCHEM 4426, Figure 6a) after initial peak assignation using NIST 11 with the understanding that they could be byproducts or remains of modern contamination until confirmed by subsequent samples. The second extraction (ARCHEM 4427, Figure 6b) clearly produced azelaic acid, cinnamic acid, camphor, and linalool from the ceramic matrix. In the third extraction (ARCHEM 4428, Figure 6c), azelaic acid, linalool, and manoyl oxide were present again confirming their presence as components of the original ancient residue. Mass spectrum fragments for oleanolic acid also clearly came out at $20.07 \mathrm{~min}$ from this third extraction. These identifications were confirmed by running chemical reference samples for each individual constituent compound, and also through comparison with the chromatographic signatures from ethnobotanical samples extracted from Artemisia, Cistus, and Tilia sourced from Crete, and from ethnographic samples extracted from modern 18th century pithoi housed in the Museum of Cretan Ethnology Research Centre, which oral history and visual inspection documented had been used to store olive oil. More data can be seen in the Supplementary Materials.

The slate of ingredients suggests that both the Mochlos and Tourloti jars held complex perfumed oils. The combination of botanicals employed suggests a surprisingly early understanding of perfume design through the creation of balanced tripartite blend, as each jar contained constituents that appear to have functioned in the perfumes as lower ("base"), middle ("heart"), and top ("head") notes, respectively. This fragrance framework of base, heart, and head notes is a governing principle in the craftsmanship of perfumes throughout history [19] and its importance was apparently recognized millennia ago. 


\subsection{Oil from Olea Europaea (Olive)}

Azelaic Acid $\left(\mathrm{C}_{9} \mathrm{H}_{16} \mathrm{O}_{4}, 188 \mathrm{MW}, 11.05 \mathrm{~min}\right.$ at Brandeis, $12.90 \mathrm{~min}$ at Penn)

Oleic Acid $\left(\mathrm{C}_{18} \mathrm{H}_{34} \mathrm{O}_{2}, 282 \mathrm{MW}, 16.70 \mathrm{~min}\right.$ at Brandeis, $24.50 \mathrm{~min}$ at Penn)

Oleic acid is a monounsaturated fatty acid (18:1) that is a pale to brownish-yellow liquid at room temperature. It is the most abundant unsaturated fatty acid found in nature, but occurs in high concentrations (55-85\%) only in olive oil from Olea europaea. Oleic acid is rarely found in animals, so it serves as a good biomarker for olive when detected in sufficient quantity in the proper context. Azelaic acid in sufficient quantity can also be a secondary biomarker for olive oil, in certain archaeological contexts. After a decade of ORA research, the project has verified that legacy objects suspected of containing olive oil in antiquity often contain large quantities of azelaic acid, a saturated dicarboxylic acid, in lieu of oleic acid. This is because oleic acid degrades to azelaic acid through oxidation scission processes that can occur once artifacts are exposed to the open environment [20-22] and discussion below. O. europaea is abundant on the island of Crete and was cultivated by 3000 B.C., or Early Minoan I [5]. In addition to being a widely available product of the Mediterranean region, textual sources from the Bronze Age and later classical periods demonstrate that olive oil was frequently used as a liquid base for perfumes [23], likely preferred in antiquity for its ability to be stored at ambient temperatures for prolonged periods without evaporating or spoiling.

\subsection{Storax Balsam from Liquidambar Orientalis (Sweetgum)}

Cinnamic Acid $\left(\mathrm{C}_{9} \mathrm{H}_{8} \mathrm{O}_{2}, 148 \mathrm{MW}, 9.61 \mathrm{~min}\right.$ at Brandeis, $10.68 \mathrm{~min}$ at Penn)

Oleanolic Acid $\left(\mathrm{C}_{30} \mathrm{H}_{48} \mathrm{O}_{3} 456 \mathrm{MW}, 20.07 \mathrm{~min}\right.$ at Brandeis)

Cinnamic acid is a carboxylic acid with strong fixative, antioxidant, and antimicrobial properties [24]. In the initial Penn Chemistry study, the compound had been noted in the Mochlos chromatograms but was not recognized at the time as cinnamic acid, instead having been categorized among the repeatedly occurring unknowns, and was retroactively identified. Cinnamic acid is a white, crystalline compound with a pleasant, leathery odor. In both the Tourloti and Mochlos perfumes, the cinnamic acid was probably obtained from the balsamic oleoresin exuded from the inner bark of Liquidambar orientalis [25], a species that contains up to 150,000 ppm cinnamic acid [26]. While cinnamic acid occurs up to 90,000 ppm in the fruit of Laurus nobilis (laurel), the complete absence of cineole, the prevailing diagnostic compound in L. nobilis (occurring up to $283,700 \mathrm{ppm}$ in its fruit), disqualifies laurel as the source botanical. Moreover, oleanolic acid, another biomarker of L. orientalis according to a GC-MS characterization of aromatic resins carried out by Modugno et al. [27], was identified in sample 4428 (i.e., the third extraction). This is one of the major biomarkers that helped determine that the extant cinnamic acid was derived from storax balsam sourced from L. orientalis, rather than storax benzoin (or benzoe) sourced from Styrax officinalis [28].

The Roman historian, Pliny the Elder, suggests that L. orientalis grew on Crete (Naturalis Historia 12.55), although it is unclear whether the species was present on the island 1200 years earlier during the LBA. Well-watered locales, such as the Kephalo Vrisi Valley (Mesa Mouliana) or the Richtis Gorge (Exo Mouliana), both nearby to Tourloti and Mochlos, would have been suitable environments judging by the regular occurrence today of Platanus orientalis (plane), which is known to grow in similar riparian ecosystems [1]. Storax balsam from L. orientalis could also have been readily sourced from the Dodecanese or southwest Anatolia (roughly $200 \mathrm{~km}$ from East Crete), where the tree grows to this day on the island of Rhodes and in the Muğla Province of the Turkish mainland, directly across from the island. Used today to anchor scents in Bourjois" "Soir de Paris" and Hermès' "Bel Ami" [19], in both the Tourloti and Mochlos perfumed oils, storax likely had the same effect of lending the final aromatic product a balsam quality to its lower and middle body (i.e., the base and heart notes). In antiquity, its antimicrobial and antioxidant qualities would have also held great value as a kind of preservative, delaying spoilage of the olive oil-based perfume. 


\subsection{Camphor from Artemisia absinthium (Wormwood)}

Camphor $\left(\mathrm{C}_{10} \mathrm{H}_{16} \mathrm{O}, 152 \mathrm{MW}, 14.19 \mathrm{~min}\right.$ at Brandeis, $15.7 \mathrm{~min}$ at Penn)

Camphor is a bicyclic terpenoid ketone that is a white (or clear) waxy crystal with a strong, pungent aromatic odor. While camphor appears in a number of species in trace amounts, the significant quantities recovered direct us to the Artemisia genus (e.g., wormwood) as the likely botanical source, where it appears in quantities upwards of 210,000 ppm [26]. While camphor also appears in particularly large quantities in Cinnamomum camphora (i.e., camphor tree), at upwards of 220,000 ppm, the latter originates in East Asia and is unlikely to occur in a Mediterranean context at this early date. Artemisia plants are hardy shrubs that grow in dry or semi-dry climates, such as the Mediterranean, and are known for their volatile oils. Due to its extremely bitter taste, plants in this genus have traditionally been used for medicinal and aromatic purposes (Dioscorides, De Materia Medica III.23.1-6), rather than flavoring [19,29]. Camphor has traditionally been used as a pest repellent and antimicrobial agent as well as the initiating top scent, or head note, in spicy perfumes such as Yves St. Laurent's "Jazz." It remained one of the most popular perfume ingredients in the early Arab world [19], affirming its long history of use in aromatics.

\subsection{Essential Oil from Coriandrum sativum (Coriander)}

Linalool $\left(\mathrm{C}_{10} \mathrm{H}_{18} \mathrm{O}, 154 \mathrm{MW}, 14.50 \mathrm{~min}\right.$ at Brandeis, $14.16 \mathrm{~min}$ at Penn)

Linalool is a terpene alcohol found in plants with a pleasant, floral scent, hence its regular use in soaps and perfumes. Researchers have also highlighted its ability to elicit physiological effects from inducing calmness to improving sleep [30]. Notably, it is the main constituent of the essential oil of Coriandrum sativum (coriander), where it occurs in concentrations upwards of 742,300 ppm [26]. Ko@í $\alpha \vee \delta \varrho o v$, or ko-ri-ja-do-no in Linear B tablet PY Un 267, has been connected with the LBA perfumed oil industries both on Crete [4] and the Greek mainland [23]. As an essential oil with some highly volatile compounds, it could have been valued as a head note in ancient perfumed oils, a role it plays today in "Gucci No. 1", Yves St. Laurent's "Jazz", and Max Factor's "Le Jardin d'Amour" [19]; however, its primary value in antiquity likely stemmed from its astringent properties, and therein its role in stypsis, a key step in oil-based perfume manufacture to which the Bronze Age and subsequent ancient sources make reference (see discussion below).

\subsection{Labdanum Amber from Cistus creticus (Cretan Rockrose)}

Manoyl Oxide $\left(\mathrm{C}_{20} \mathrm{H}_{34} \mathrm{O}, 290 \mathrm{MW}, 17.51 \mathrm{~min}\right.$ at Brandeis, $23.71 \mathrm{~min}$ at Penn)

Manoyl oxide is a diterpenoid ether found in the Cistaceae (rockrose) and Pinaceae (pine) families, and could arguably represent either. Cistaceae has a long history, however-in the Mediterranean, in general, and Crete, in particular (Herodotus, The Histories 3.112) - as a traditional ingredient in perfumes and, moreover, was a species known to and used by the LBA Minoans themselves $[4,31]$. Manoyl oxide is found (in higher quantities than in Pinaceae) in labdanum, a highly viscous resinous material obtained from Cistus creticus, or Cretan rockrose, a plant that is depicted on an LM IA (ca. 1600 B.C.) fresco from Akrotiri, Thera [31-33]. C. creticus is native to the island of Crete and has several well-known cultivars including one termed "Lasithi", named after the general region in which Tourloti resides. This Lasithi cultivar seems likely to be the source of the manoyl oxide used in both the Tourloti and Mochlos preparations, as it grows abundantly in the western Siteia foothills to this day.

Ancient Egyptian and Greek sources enumerate labdanum's many medicinal and aromatic uses [34], but it is best known in the present day as "amber" in perfumes such as Taittinger's "Baccarat", Yves St. Laurent's "Jazz", and Calvin Klein's "One" [19]. It is one of the main substitutes for ambergris in the modern perfume industry as a foundational lower, or base, note, and serves also a fixative to help retain scents, as it undoubtedly did for the perfumed oils of LBA East Crete. Some of labdanum's compounds can also serve as a middle, or heart, note just as in the case with storax balsam, and this 
versatility may explain its use in nearly a third of all modern perfumes [19]. It has filled this role for the past century as an original main ingredient for the so-called chypre (i.e., Cyprus) family of perfumes, such as Hermès" "Bel Ami", which coincidentally uses storax as a complementary base note in a similar fashion to our ancient perfumed oils.

\subsection{Tilleul from Tilia (Linden)}

\section{Docosane $\left(\mathrm{C}_{22} \mathrm{H}_{46}, 310 \mathrm{MW}, 20.70\right.$ at Penn)}

Docosane is an alkane hydrocarbon found in high concentrations in flower extracts, notably from the Tilia genus, or linden, which according to palynological studies grew on Crete at least during the earlier LBA [35-37]. Its identification is based not only on the solitary presence of the biomarker docosane, but also by careful consideration of the presence or absence of companion diagnostic compounds (e.g., isopulegol, a monoterpene alcohol that when appearing concurrently with docosane would instead suggest Lilium, or the lily plant [38]). These holistic phytochemical considerations make Tilia the most likely candidate to explain the concentration of docosane, a conclusion verified by the matching chromatographic signature produced from an ethnobotanical Tilia sample collected on Crete. ORA evidence for Tilia was recovered only from the Mochlos samples and absent from Tourloti.

In addition to its use as a treatment for atherosclerosis, Tilia also has antimicrobial properties [39], but the double-flowered blossom from this genus is best known for its aromatic compounds used to make perfumes $[19,40]$. Its fragrance, known primarily today by the industry as the heart-note infusion "tilleul" and used in perfumes such as Bourjois' "Soir de Paris" and Jesus Del Pozo's "Duende", is often described as reminiscent of citrus or honeysuckle, and as such could have also served as a head note. It is notable that Bourjois' "Soir de Paris" employs both storax and tilleul as complementary base and heart notes, respectively [19], echoing the pairing used in the Mochlos perfumed oil [4].

\subsection{Summary of ORA Results}

The collective chemical composition of the residues from the Mochlos and Tourloti objects suggests that both contained (or were used in the production of) a sophisticated olive oil-based perfume infused with Cistus labdanum amber (base and heart notes), Liquidambar storax balsam (base and heart notes), Artemisia camphor (a head note), and Coriandrum essential oil (a head note); all are botanicals that would have been locally available in East Crete or nearby regions such as Rhodes. The consistency between the two perfume "recipes" - both in regard to their ingredients and the techniques of their manufacture - can also be said to be a meaningful indicator of cultural continuity over the course of several centuries, where luxury items offered one means by which to negotiate status both during and after the demise of the Cretan Bronze Age palatial centers [1,41].

The results highlight the exciting potential for organic residue studies to illustrate both products and processes, here particularly related to Bronze Age perfume manufacture. The use of Coriandrum in both the Mochlos and Tourloti vessels is particularly meaningful in that it likely reflects the practice of stypsis, the treatment of the base oil with an astringent in a two-stage process to make it more receptive to infusion with aromatic compounds [23] (with the added bonus of a complementary head note). This technique was employed in the perfumeries of the Late Bronze Mycenaean palaces, as documented at Pylos in Linear B tablets Un 267 and Vn 130 [23,42], and is now archaeometrically confirmed [1,4]. In this vein, it is significant that the linalool is present in the completed product-the perfumed oil present in both the Mochlos amphora and the Tourloti stirrup jar-but not in the Mochlos vat. Its absence might simply reflect the rapid volatilization of the compound as it was exposed to air in the open vat, but this seems unlikely given the high boiling point of this compound-thus its lower relative volatility - and furthermore given that the Tourloti jar had similarly been exposed to air for over a century, and yet contained a relative abundance (RA) of linalool nearly identical to the Mochlos amphora. Linalool's absence from the vat may instead show that the vat was not employed for stypsis, but instead used in some other aspect of the perfume manufacturing process, perhaps the infusion of 
the primary constituent aromatics. The comparable quantities of linalool in the Mochlos and Tourloti jars-in the neighborhood of 15\% RA for both-may reflect the absorption potential of olive oil in relation to linalool, or infer something about the proportions of the ancient recipe. While the practice of stypsis needs to be explored more fully, it may also be that biomarkers for coriander could be used to distinguish perfumed oils from other lipid-based organic commodities in the Bronze Age Aegean world and beyond. The comprehensive ORA results, thus, offer unique insight into Bronze Age chaine opératoire, elements of which could have implications for further ORA studies.

Additionally of note is the fact that the earlier Mochlos vessels contained one additional ingredient, tilleul from Tilia blossoms, the presence of which was marked by significant quantities of the compound docosane. Additional vessels containing docosane, including cooking pots, were found immediately outside the Vat Room in the same Mochlos workshop and were probably used for maceration, or heated steeping, of the Tilia blossoms [4]. The absence of tilleul in the later Tourloti perfume may reflect a shift in the botanical profile of the region from LM IB to IIIC (ca. 1500-1175 B.C.), and in particular a move away from preferential utilization of the plant in the wake of political and social change in East Crete in the intervening centuries. However, it is significant that the LM III-EIA pollen cores from the island echo the same pattern as the perfumes; Tilia disappears at the end of the LBA. The disappearance of Tilia from the palynological record was, in fact, specifically connected with climatic shifts at the end of the Bronze Age that diminished the tree's natural habitat [36]. It is, therefore, possible that the absence of tilleul from the Tourloti perfume could be a direct reflection of climate change (e.g., aridification) that occurred at the end of the Late Bronze Age [43-48].

The results of our ORA study, thus, shed new light on elite behavior, manufacturing processes, and cultural patterns at the end of the Bronze Age, while also hinting at ORA's exciting and underdeveloped potential as a tool for paleoecological reconstruction.

\section{Discussion}

The presence of complex perfumed oils with multiple scent layers, or notes, in the LM IB Mochlos and LM IIIC Tourloti vessels offers a window into the structural and market forces that shaped demand and production of these expensive, value-added commodities during the Bronze Age [1,4]. From an archaeometric perspective, however, the comparative Tourloti and Mochlos results are in many ways even more exciting. They are particularly important in that they demonstrate the value and viability of ORA samples taken from legacy objects, even those for which the "chain of custody" cannot be completely known. They moreover illuminate patterns in degradation processes and sample variation that in turn have potentially significant implications for future extractive and interpretive methodologies, upon which we offer a few preliminary comments.

\subsection{Compound Expressions in Legacy and Newly Excavated Objects}

Diagnostic legacy compounds, which are typically lipids, suffer from long-term autoxidation processes and therein degradation, recognition of which is essential for successful interpretation $[49,50]$. Oleic acid, for example, the major diagnostic and prevalent fatty acid of olive oil, degrades into azelaic acid and nonanoic acid under oxidizing conditions, a process noted in several artifact residue studies $[1,20,21]$. Our Tourloti case study demonstrates this lipid oxidation in stark terms: The residues from the freshly excavated Mochlos objects preserved substantial quantities of oleic acid and no azelaic acid. By contrast, in the legacy Tourloti jar the degradation is virtually total, and azelaic acid constitutes the largest peak across all chromatograms.

This same phenomenon was detected in early ARCHEM data from a sixth century B.C. olive press installation from Azoria in East Crete. This installation was discovered in the larger west room of a two-room structure (D300) from the Service Building, excavated in 2006 under the direction of D. Haggis and M. Mook [51]. D300 contained overwhelming archaeological evidence for the processing and pressing of olives: a press bench, press beam sockets, numerous weights, and a basin, found together with substantial quantities of olive pits-including seeds from press-cake. The site was 
eventually abandoned and destroyed, although apparently not before valuables had been removed [52]. Whereas ORA samples taken from modern olive oil jars and presses on Crete have oleic acid as their predominant compound, the ORA samples taken from the basin, querns, and surrounding soil from the olive press installation at Azoria were dominated by overwhelming evidence for azelaic acid. Indeed, the pressing process during the lifetime of the room would have presumably ensured that the incidental detritus and remnant oils from olives were subjected to constant, unmitigated exposure to air, offering continuous opportunity for natural aerobic processes such as oxidation and degradation.

As a monounsaturated fatty acid, the three-phase overall mechanism (i.e., 1.) initiation, or formation of free radicals; 2.) propagation, or free-radical chain reactions; and 3.) termination, or formation of nonradical products $[49,53]$ ) of oleic acid oxidation and therein the rate of degradation, is affected by successive reactions, of which azelaic acid is a dominant terminal nonradical product $[1,20]$. The OpenARCHEM project is currently conducting a series of fatty acid degradation studies at the Wesleyan University Department of Chemistry in order to better characterize these mechanisms, the nature and timing of which have yet to be comprehensively documented. As we come to understand the processes, which facilitate and catalyze oleic acid degradation, it is possible that the product distribution ratios between oleic and azelaic, and the peroxide value of various intermediary hydroperoxides [53], could eventually serve as meaningful indicators of the length of time for which an object was exposed in antiquity and therein shed light on site use or abandonment processes. It may be possible, for example, that the better preservation of oleic acid in the Mochlos perfume paraphernalia may be due in part to the fact that the space was quickly sealed by the unexpected collapse of the building during the powerful LM IB (ca. 1500 B.C.) earthquake that hit the town [3,4]. These mechanisms clearly demand systematic study, but may eventually also be a useful means by which one could determine something about the history of legacy vessels when the object biography is otherwise opaque.

\subsection{Location, Location, Location: Considering Vessel Topography}

As we move to refine our methodologies, it is worth noting-and attempting to better understand - the nature of certain variabilities exhibited among extractions from the same vessel and their possible relationship to the location at which sampling occurred $[1,14]$. One of the more striking results from within the Mochlos group, for example, was the variable evidence for Tilia. Docosane was present in quantities of $8.64 \%$ RA in samples taken from the lowest point of the Mochlos vat (Table 1), but was absent, or appeared only in trace quantities, from other areas of the vat such as the vessel spout, despite the use of the same solvent. These distinctions are arguably meaningful reflections of the vessel use, as the greatest abundance was found in the vat base where the contents would have most likely pooled and therein had greater opportunity to permeate the clay, as opposed to the sides, which would have had more sporadic exposure to the contents. Similar disparities were noted in relation to the presence of cholesterol, which was detected only in the vertical, conical spout of the vat, and which points to the use of wool as a filter to strain macroscopic impurities [23]. The Tourloti jar, which being a complete closed form was sampled using the swish method, also showed some variability among the three extractions taken, as indeed the total ion chromatograms (TIC) demonstrate. Note, for example the absence of cinnamic acid and camphor in extractions one and three (Figure 6, Table 1). The qualitative differences between the Tourloti samples are not yet fully understood, but do not appear to be related to degradation processes. It may be that, as with the Mochlos objects, these discrepancies are related to the site of sampling, and perhaps to the variable properties and depositional densities and locations of the compounds within, which might differentially permeate the base, side, and shoulders of the jar. Such variability suggests the importance of considering the shape, use, fabric, and function of vessels when sampling organic residues, and the importance of multiple extractions that target different areas of a vessel to ensure the broadest possible coverage and therein greater accuracy. 


\subsection{Rehabilitating Legacy Objects}

Above all, the case study above demonstrates the viability and value of legacy objects, provided proper consideration is afforded to object biography and potential contaminants, whether natural or anthropogenic. It thus offers an important corrective to past criticisms of ORA that have dismissed the utility of such artifacts. The companion volumes Minoans and Mycenaeans: Flavours of Their Times [54] and Archaeology Meets Science: Biomolecular Investigations in Bronze Age Greece [55], two of the most prominent ORA publications in Mediterranean studies, were particularly influential in conveying this message. These collaborative volumes, which assembled contributions from seven different laboratory groups utilizing wildly varying extraction methodologies and instrumentation (with no evident coordination or standardization), allowed for easy criticism of ORA, and especially of ORA results from legacy objects because of their greater risk of exposure to anthropogenic and environmental contaminants [56,57]. The volumes shed welcome light on Bronze Age organic commodities and drew necessary attention to potentially problematic contaminants, but included unqualified critiques that essentially encouraged a "baby-with-the-bathwater" dismissal of ORA, casting doubt on the viability of ORA studies in general and legacy objects in particular.

It is certainly clear that better ORA results are usually obtained from artifacts recovered from ongoing, or at least recent, excavations $[5,6,13,18,58]$, if only because sampling conditions and object biographies can be better controlled and understood. Yet the case study presented herein showcases a legacy object that in many respects reproduces a result obtained from a freshly-excavated object, thus demonstrating the inherent value of this class. The compounds in legacy objects may appear in diminished quantities-both in number and peak strength-relative to modern standards or freshly-excavated examples, but if properly scaled the peaks are discernible and appear to offer meaningful indicators of the presence and proportions of compounds, as the RA of linalool demonstrates (see above).

Insofar as contaminants are concerned, although there is no foolproof methodology that can guarantee that results from a legacy vessel—or indeed any object—will be free from contamination, our work does point towards a few steps that can be taken to better ensure a sample's reliability and viability, even in circumstances where the full object biography is unknown. Foremost among these is an ability to predict, identify, and screen for common contaminants, such as plasticizers (e.g., phthalates, which are not naturally occurring and can reflect the storage of an object in a plastic bag), as was the case with portions of the Mochlos vat spout. In addition, it may be possible to screen for impurities that are most likely to be present on the outermost oxidized surface of the organic residues, through the use of multiple extractions [1], and by consideration of the geological profile of the clay itself [14]. This latter, too, is a process presently under study by the OpenARCHEM project at the Massachusetts Institute of Technology Center for Materials Research in Archaeology and Ethnology. Most important, it is essential that the condition, quality, and storage of any sample, whether taken from a newly excavated or legacy object, be fully described and acknowledged in any publication. With transparency and proper consideration of object biographies and degradation processes, legacy objects can indeed yield valuable and verifiable results.

Such results are most meaningful when they can be placed in conversation with new samples, or considered as constituents within a larger ecosystem of chemically comparable or contemporary samples. This is often difficult: ORA studies tend to be siloed, published singly in various specialized outlets or buried in archaeological site reports, preventing aggregate study. It is clear that the field would benefit from a common repository that might best facilitate the comparison and sharing of ORA results. The OpenARCHEM archaeometric database [59] was created specifically in response to this challenge. Using the original ARCHEM project library of chromatographic data as its core, which includes over 5000 ORA samples, the OpenARCHEM database is designed to be a platform by which scholars of antiquity across many disciplines and regions can review, compare, and integrate ORA into their own work. Each entry presents the results from a single extraction, and includes not only diagnostic compounds with their GC-MS chromatograms and links to NIST reference chromatograms, 
but also information about the type of artifact sampled, its quality, condition, and storage history, as well as links to ethnohistorical textual sources that discuss the botanical species identified.

The inclusion of these different categories of information offers routes by which the scientist, the social scientist, and the humanist can ask different kinds of questions of organic data-the scientist searching by chemical compound, for example, or the humanist by ancient author. It also allows for focused comparisons, whether between samples from similar jar types or by those with comparable object histories, thus aiding in further refinement of archaeometric methodologies. Through such data-sharing, chemical signatures that went undetected or unrecognized in early studies may become identifiable (as was the case with our cinnamic acid at Mochlos), and larger patterns, such as connections between contents and their containers, can become visible. Collaborative repositories and archaeometric communities such as these tap into the promise of big data [59,60], and are a resource by which ORA can be engaged in service to larger archaeological questions.

\section{Conclusions}

ORA is evolving far beyond its traditional lab-bound role to become an integrated element of field methodology and a fundamental part of archaeological research design. It moreover stands ready to harness the power of big data to address larger questions of economy, technology, ecology, and environment. The comparative case study above demonstrates the value of legacy objects as candidates for ORA, and highlights new questions such data can be called upon to ask. The development of responsible and nuanced methods for the sampling of legacy objects, when paired with careful consideration of degradation pathways, can substantially broaden the range of viable artifacts for study and therein the field of inquiry. Yet whether from new or legacy artifacts, ORA results must be considered within a comprehensive ecosystem of archaeological, archaeometric, and ethnographic data.

Supplementary Materials: The following are available online at www.openarchem.org, additional chromatographic, ethnobotanical, and ethnohistorical data.

Author Contributions: The analyses and interpretation of the results were coordinated by A.J.K. and carried out together with K.J.B. A.J.K. and K.J.B. wrote and revised the manuscript drafts. Both authors read and approved the final manuscript.

Funding: This research was supported by the University of Pennsylvania (Penn Museum, Department of Chemistry, and School of Arts and Sciences), Wesleyan University (Department of Chemistry, Archaeology Program), Brandeis University (Office of the Dean of Arts and Sciences, Department of Chemistry, Department of Classical Studies), Institute for Aegean Prehistory, and Archaeological Institute of America.

Acknowledgments: We thank the University of Pennsylvania Department of Chemistry for incubating the analytical facets of the ARCHEM project at its start in 2003. Without the guidance of G. Molander and G. Palladino, the project would not have materialized. At the Penn Museum, C. B. Rose, P. P. Betancourt, and L. Makowsky of the Mediterranean Section and J. Houser Wegner, J. W. Wegner, and D. Silverman of the Egyptian Section have been instrumental in supporting the project. L. Grant, M.-C. Boileau, and the Penn Museum Scientific Testing Committee have offered us valuable feedback and the use of the Conservation Department facilities. E. H. Cline, L. Hitchcock, C. R. Floyd, and A. M. Berlin have offered steady advice during the startup of the OpenARCHEM project and its archaeometric database. A. K. Krohn and A. M. Crandall, as senior staff members of the OpenARCHEM Project, continue to offer their unfailing assistance. P. Der Manuelian and J. A. Greene supported this study by arranging our appointments as research associates of the Harvard Semitic Museum. H. N. Lechtman facilitated access to MIT resources through its Center for Materials Research in Archaeology and Ethnology. We benefited greatly from conversations with A. Kanta, J. Moody, and A. Sarpaki concerning the rich flora of Crete, A. Yasur-Landau and P. Waiman-Barak concerning the same in the Southern Levant, and I. Liritzis concerning the ecology of Southern Phokis. J. G. Younger generously shared his map of East Crete. Colleagues at our institutions-W. Gilstrap, J. Meanwell, C. Parslow, D. Charles, A. O. Koloski-Ostrow, L. Muellner, B. Snider, C. Thomas, C. Wade, M. Sheehy, and I. Roy-have been our pillars of support. We especially thank T. D. Westmoreland and A. Roberts at Wesleyan University Chemistry for their support of OpenARCHEM degradation studies. In Crete, AJK received support from the INSTAP Study Center for East Crete, in collaboration with the 24th Ephorate of Prehistoric and Classical Antiquities and the American School of Classical Studies at Athens, and the Museum of Cretan Ethnology Research Centre, under the directorship of C. Vallianos.

Conflicts of Interest: The authors declare no conflicts of interest. 


\section{Abbreviations}

GC-MS—gas chromatography-mass spectrometry; ORA—organic residue analysis; EI—electron ionization; $\mathrm{CI}$-chemical ionization; TIC - total ion chromatogram; RA—relative abundance; AA—absolute abundance; LBA—Late Bronze Age; LM—Late Minoan; EIA—Early Iron Age.

\section{References}

1. Koh, A.J.; Birney, K.J. Organic Compounds and Cultural Continuity: The Penn Museum Late Minoan IIIC Stirrup Jar from Tourloti. Mediterr. Archaeol. Archaeom. 2017, 17, 19-33. [CrossRef]

2. OpenARCHEM Project. Available online: http:/ / openarchem.com (accessed on 19 December 2018).

3. Soles, J.S.; Mochlos, I.A. Period III. Neopalatial Settlement on the Coast: The Artisans' Quarter and the Farmhouse at Chalinomouri.; INSTAP Academic Press: Philadelphia, PA, USA, 2003.

4. Koh, A.J. Wreathed in a Fragrant Cloud: Reconstructing a Late Bronze Age Aegean Workshop of Aromata. Ph.D. Dissertation, University of Pennsylvania, Philadelphia, PA, USA, 2006.

5. Koh, A.J.; Betancourt, P.P. Wine and Olive Oil from an Early Minoan Hilltop Fort. Mediterr. Archaeol. Archaeom. 2010, 10, 15-23.

6. Koh, A.J.; Yasur-Landau, A.; Cline, E.H. Characterizing a Middle Bronze Palatial Wine Cellar from Tel Kabri, Israel. PLoS ONE 2014, 9, e106406. [CrossRef] [PubMed]

7. Seager, R.B. Excavations on the Island of Mochlos, Crete in 1908. Am. J. Archaeol. 1909, 13, 271-303. [CrossRef]

8. Betancourt, P.P. Minoan Objects Excavated from Vasilike, Pseira, Sphoungaras, Priniatikos Pyrgos, and Other Sites; University Museum, University of Pennsylvania: Philadelphia, PA, USA, 1983.

9. Becker, M.J.; Betancourt, P.P. Richard Berry Seager: Archaeologist and Proper Gentleman; University of Pennsylvania Museum of Archaeology and Anthropology: Philadelphia, PA, USA, 1997.

10. Gerhardt, K.O.; Searles, S.; Biers, W.R. Corinthian Figure Vases: Non-destructive Extraction and Gas Chromatography-Mass Spectrometry. In Organic Contents of Ancient Vessels: Materials Analysis and Archaeological Investigation; Biers, W.R., McGovern, P., Eds.; MASCA Research Papers in Science and Archaeology 7; University of Pennsylvania Museum of Archaeology and Anthropology: Philadelphia, PA, USA, 1990; pp. 41-50.

11. Biers, W.R.; Gerhardt, K.O.; Braniff, R.A. Lost Scents: Investigations of Corinthian "Plastic" Vases by Gas Chromatography-Mass Spectrometry; MASCA Research Papers in Science and Archaeology; MASCA, University of Pennsylvania Museum of Archaeology and Anthropology: Philadelphia, PA, USA, 1994; Volume 11.

12. Evershed, R.P.; Vaughan, S.J.; Dudd, S.N.; Soles, J.S. Fuel for Thought? Beeswax in Lamps and Conical Cups from Late Minoan Crete. Antiquity 1997, 71, 979-985. [CrossRef]

13. Yasur-Landau, A.; Cline, E.H.; Koh, A.J.; Ratzlaff, A.; Goshen, N.; Susnow, M.; Waiman-Barak, P.; Crandall, A.M. The Wine Storage Complexes at the Middle Bronze II Palace of Tel Kabri: Results of the 2013 and 2015 Seasons. Am. J. Archaeol. 2018, 122, 309-338. [CrossRef]

14. Goldenberg, L.; Neumann, R.; Weiner, S. Microscale Distribution and Concentration of Preserved Organic Molecules with Carbon-Carbon Double Bonds in Archaeological Ceramics. J. Archaeol. Sci. 2014, 42, 509-518. [CrossRef]

15. Evershed, R.P. Experimental Approaches to the Interpretation of Absorbed Organic Residues in Archaeological Ceramics. World Archaeol. 2008, 40, 26-47. [CrossRef]

16. Mills, J.S.; White, R. The Organic Chemistry of Museum Objects, 2nd ed.; Butterworth-Heinemann: Oxford, UK; Woburn, MA, USA, 1999.

17. Colombini, M.P.; Modugno, F.; Ribechini, E. GC/MS in the Characterization of Lipids. In Organic Mass Spectrometry in Art and Archaeology; Colombini, M.P., Modugno, F., Eds.; Wiley: Chichester, UK, 2009; pp. 191-214.

18. Koh, A.J. Methods and Approaches: Organic Residue Analysis. In The Blackwell Companion to Aegean Art and Architecture; Hitchcock, L., Davis, B., Eds.; Blackwell: Oxford, UK, in press.

19. Groom, N. New Perfume Handbook, 2nd ed.; Blackie Academic and Professional: London, UK, 1997.

20. Regert, M.; Bland, H.A.; Dudd, S.N.; Van Bergen, P.F.; Evershed, R.P. Free and Bound Fatty Acid Oxidation Products in Archaeological Ceramic Vessels. Proc. R. Soc. Lond. 1998, 265, 2027-2032. [CrossRef] 
21. Ribechini, E.; Modugno, R.; Baraldi, C.; Baraldi, P.; Colombini, M.P. An Integrated Analytical Approach for Characterizing an Organic Residue from an Archaeological Glass Bottle Recovered in Pompeii (Naples, Italy). Talanta 2008, 74, 555-561. [CrossRef]

22. Godard, A.; De Caro, P.; Thiebaud-Roux, S.; Vedrenne, E.; Mouloungui, Z. New Environmentally Friendly Oxidative Scission of Oleic Acid into Azelaic Acid and Pelargonic Acid. J. Am. Oil Chem. Soc. 2013, 90, 133-140. [CrossRef]

23. Shelmerdine, C.W. The Perfume Industry of Mycenaean Pylos; Paul Åströms Förlag: Göteborg, Sweden, 1985.

24. Sova, M. Antioxidant and Antimicrobial Activities of Cinnamic Acid Derivatives. Mini Rev. Med. Chem. 2012, 12, 749-767. [CrossRef] [PubMed]

25. Feliks, Y. The Incense of the Tabernacle. In Pomegranates and Golden Bells: Studies in Biblical, Jewish, and Near Eastern Ritual, Law, and Literature in Honor of Jacob Milgrom; Wright, D.P., Freedman, D.N., Hurvitz, A., Eds.; Eisenbrauns: Winona Lake, IN, USA, 1995; pp. 125-149.

26. Dr. Duke's Phytochemical and Ethnobotanical Databases. U.S. Department of Agriculture, Agricultural Research Service 1992-2016. Available online: http://phytochem.nal.usda.gov (accessed on 19 December 2018).

27. Modugno, F.; Ribechini, E.; Colombini, M.P. Aromatic Resin Characterisation by Gas Chromatography-Mass Spectrometry: Raw and Archaeological Materials. J. Chromatogr. A 2006, 1134, 298-304. [CrossRef] [PubMed]

28. Birney, K.J.; Koh, A.J. Adventures in Storax. Full Spectrum: Micro-Publications from OpenARCHEM. 2018. Available online: https://openarchem.com/2018/10/16/adventures-in-storax (accessed on 19 December 2018).

29. Nezhadali, A.; Akbarpour, M.; Zarrabi, S.B. Chemical Composition of the Essential Oil from the Aerial Parts of Artemisia Herba. J. Chem. 2008, 5, 557-561. [CrossRef]

30. Elsharif, S.A.; Banerjee, A.; Buettner, A. Structure-odor relationships of linalool, linalyl acetate and their corresponding oxygenated derivatives. Front. Chem. 2015, 3, 57. [CrossRef] [PubMed]

31. Vlachopoulos, A. The Wall Paintings from the Xeste 3 Building at Akrotiri: Towards an Interpretation of the Iconographic Programme. In Horizon: A Colloquium on the Prehistory of the Cyclades; Brodie, N., Doole, J., Gavalas, G., Renfrew, C., Eds.; McDonald Institute for Archaeological Research: Cambridge, UK, 2008; pp. 451-465.

32. Marinatos, S. Excavations at Thera VII 1973 Season; Archaeological Society at Athens: Athens, GR, USA, 1976.

33. Chapin, A. The Lady of the Landscape: An Investigation of Aegean Costuming and the Xeste 3 Frescoes. In Reading a Dynamic Canvas: Adornment in the Ancient Mediterranean World; Colburn, C.S., Heyn, M.K., Eds.; Cambridge Scholars Publishing: Newcastle, UK, 2008; pp. 48-83.

34. Oller-López, J.L.; Rodriguez, R.; Cuerva, J.M.; Oltra, J.E. Composition of the Essential Oils of Cistus ladaniferus and, C. monspeliensis from Morocco. J. Essent. Oil Res. 2005, 8, 455.

35. Moody, J.; Rackham, O.; Rapp, G. Environmental Archaeology of prehistoric NW Crete. J. Field Archaeol. 1996, 23, 273-297.

36. Moody, J. Hinterlands and Hinterseas: Resources and Production Zones in Bronze Age and Iron Age Crete. Br. Sch. Athens Stud. 2012, 20, 233-271.

37. Moody, J. Prehistoric and Historic Climate and Weather in (East) Crete. In A Cretan Landscape through Time: Priniatikos Pyrgos and Environs; Molloy, B., Duckworth, C., Eds.; British Archaeological Reports; Archaeopress: Oxford, UK, 2014; pp. 23-30.

38. Farsam, H.; Amanlou, M.; Amin, G.; Nezamivand-Chegini, G.; Salehi-Surmaghi, M.-H.; Abbas, S. Anatomical and Phytochemical Study of Lilium ledebourii (Baker) Boiss.; a Rare Endemic Species in Iran. Daru J. Pharm. Sci. 2003, 11, 164-170.

39. Gönül, S.; Karapinar, M. Inhibitory effect of linden flower (Tilia flower) on the growth of foodborne pathogens. Food Microbiol. 1987, 4, 97-100. [CrossRef]

40. Vidal, J.P.; Richard, H. Characterization of Volatile Compounds in Linden Blossoms Tilia cordata Mill. Flavours Fragr. 1986, 1, 7-62.

41. Hitchcock, L.A.; Maeir, A.M. Lost in Translation: Urbanism in Post-Palatial Crete at the End of the Bronze Age. In From Static Data to Dynamic Processes: New Perspectives on Minoan Architecture and Urbanism; Knappett, C., Letesson, Q., Eds.; Oxford University: Oxford, UK, 2017; pp. 289-333. 
42. Palaima, T. Pylos Tablet Vn 130 and the Pylos Perfume Industry. In KE-RA-ME-JA: Studies Presented to Cynthia, W. Shelmerdine; Nakassis, D., Gulizio, J., James, S.A., Eds.; INSTAP Academic Press: Philadelphia, PA, USA, 2014; pp. 83-90.

43. Kaniewski, D.; Paulissen, E.; Van Campo, E.; Weiss, H.; Otto, T.; Bretschneider, J.; Van Lerberghe, K. Late Second-Early First Millennium BC Abrupt Climate Changes in Coastal Syria and Their Possible Significance for the History of the Eastern Mediterranean. Quat. Res. 2010, 74, 207-215. [CrossRef]

44. Drake, B.L. The Influence of Climatic Change on the Late Bronze Age Collapse and the Greek Dark Ages. J. Archaeol. Sci. 2012, 39, 1862-1870. [CrossRef]

45. Kaniewski, D.; Van Campo, E.; Guiot, J.; Le Burel, S.; Otto, T.; Baeteman, C. Environmental Roots of the Late Bronze Age Crisis. PLoS ONE 2013, 8, e71004. [CrossRef]

46. Cline, E.H. 1177 B.C.: The Year Civilization Collapsed; Turning Points in Ancient History; Princeton University: Princeton, NJ, USA, 2014.

47. Langgut, D.; Finkelstein, I.; Litt, T.; Harald Neumann, F.; Stein, M. Vegetation and Climate Changes during the Bronze and Iron Ages ( 3600-600 BCE) in the Southern Levant Based on Palynological Records. Radiocarbon 2015, 57, 217-235. [CrossRef]

48. Knapp, A.B.; Manning, S.W. Crisis in Context: The End of the Late Bronze Age in the Eastern Mediterranean. Am. J. Archaeol. 2016, 120, 99-149. [CrossRef]

49. Simic, M.G. Free radical mechanisms in autoxidation processes. J. Chem. Educ. 1981, 58, 125. [CrossRef]

50. Porter, N.A.; Caldwell, S.E.; Mills, K.A. Mechanisms of Free Radical Oxidation of Unsaturated Lipids. Lipids 1995, 30, 277-290. [CrossRef]

51. Haggis, D.C.; Mook, M.S.; Fitzsimons, R.D.; Scarry, C.M.; Snyder, L.M.; West, W.C. Excavations in the Archaic Civic Buildings at Azoria in 2005-2006. Hesperia 2011, 80, 1-70. [CrossRef]

52. Haggis, D.C.; Mook, M.S.; Fitzsimons, R.D.; Scarry, C.M.; Snyder, L.M. The Excavation of Archaic Houses at Azoria in 2005-2006. Hesperia 2011, 80, 431-489. [CrossRef]

53. Porter, N.A.; Mills, K.A.; Carter, R.L. A Mechanistic Study of Oleate Autoxidation: Competing Peroxyl H-Atom Abstraction and Rearrangement. J. Am. Chem. Soc 1994, 116, 6690-6696. [CrossRef]

54. Tzedakis, Y. Martlew, H. Minoans and Mycenaeans: Flavours of Their Times. In Catalogue of the Exhibition; Kapon: Athens, Greece, 2002.

55. Tzedakis, Y.; Martlew, H.; Jones, M.K. (Eds.) Archaeology Meets Science: Biomolecular Investigations in Bronze Age Greece; Oxbow Books: Oxford, UK, 2008.

56. Beeston, R.F.; Palatinus, J.; Beck, C.W. Organic Residue Analysis: Pseira. In Archaeology Meets Science: Biomolecular Investigations in Bronze Age Greece; Tzedakis, Y., Martlew, H., Jones, M.K., Eds.; Oxbow Books: Oxford, UK, 2008; pp. 74-86.

57. Barnard, H.; Ambrose, S.A.; Beehr, D.E.; Forster, M.F.; Lanehart, R.E.; Malainey, M.E.; Parr, R.E.; Rider, M.; Solazzo, C.; Yohe, R.M. Mixed results of seven methods for organic residue analysis applied to one vessel with the residue of a known foodstuff. J. Archaeol. Sci. 2007, 34, 28-37. [CrossRef]

58. Perruchini, E.; Glatz, C.; Hald, M.M.; Casana, J.; Toney, J.L. Revealing Invisible Brews: A New Approach to the Chemical Identification of Ancient Beer. J. Archaeol. Sci. 2018, 100, 176-190. [CrossRef]

59. Koh, A.J.; Birney, K.J. (Eds.) OpenARCHEM Archaeometric Database. Available online: http:/ / openarchem. org (accessed on 19 December 2018).

60. Berlin, A.M. (Ed.) Levantine Ceramics Project. Available online: http:/ /levantineceramics.org (accessed on 19 December 2018).

(C) 2019 by the authors. Licensee MDPI, Basel, Switzerland. This article is an open access article distributed under the terms and conditions of the Creative Commons Attribution (CC BY) license (http:/ / creativecommons.org/licenses/by/4.0/). 